\title{
VIOLÊNCIA, EDUCAÇÃO E SOCIEDADE: O BULLYING NA CONCEPÇÃO DE EDUCADORES EM ANANINDEUA (PA)
}

\author{
VIOLENCE, EDUCATION AND SOCIETY: BULLYING \\ IN THE CONCEPTION OF EDUCATORS IN ANANINDEUA (PA) \\ VIOLENCIA, EDUCACIÓN Y SOCIEDAD: LA INTIMIDACIÓN \\ EN LA CONCEPCIÓN DE EDUCADORES EN ANANINDEUA (PA)
}

\author{
Rosely CABral Giordano \\ LANA JenNyfFer SANTOS NAZARETH ${ }^{\mathrm{I}}$
}

\begin{abstract}
Resumo O tema do ensaio - vinculado à pesquisa Violência Escolar: discriminação, bullying e responsabilidade (CROCHÍK, 2013) - incide sobre a violência escolar presente no bullying. Examinamos, especificamente, concepções de educadores (professores e coordenadores pedagógicos) das $8^{\mathrm{a}}$ séries $/ 9^{\circ}$. anos de três escolas públicas do município de Ananindeua (PA) acerca de questões envolvidas no bullying. Tais concepções foram levantadas por meio de entrevistas semiestruturadas e se voltam à percepção desses educadores acerca das causas do bullying; a respeito do perfil dos alunos que agridem e/ou são agredidos; sobre se os alunos em situação de inclusão são vitimizados tanto quanto os demais alunos nas escolas em que trabalham e, finalmente, com relação às possíveis ações para combater o bullying escolar. A análise das referidas concepções é realizada a partir do quadro de referências da Teoria Crítica da Sociedade, particularmente, da investigação social empírica, conforme proposições de Adorno, Horkheimer e Marcuse.

Palavras-chave: Teoria Crítica da Sociedade; Violência Escolar; Discriminação e preCONCEITO.
\end{abstract}

Abstract The theme of the essay - related to the investigation School violence: discrimination, bullying and responsibility (CROCHÍK, 2013) - focuses on school violence in school bullying. We examined in particular the conceptions of educators (teachers and pedagogical coordinators) of the 8th series/9th years of three public schools in the city of Ananindeua (PA) on issues related to bullying. Such conceptions were raised through semi-structured interviews and focused on the perception of these educators about: the causes

Universidade Federal do Pará (UFPA), Belém/PA - Brasil 
of intimidation; the profile of students who are attacked and / or attacked; on whether the students in the situation of inclusion are victimized as much as the other students in the schools in which they work and, finally, on possible actions to combat bullying. The analysis of these conceptions is carried out from the framework of the Critical Theory of Society, particularly the empirical social research, according to Adorno, Horkheimer and Marcuse. Key-words: Critical Theory of Society; School Violence; Discrimination and prejudice.

RESUMen El tema del ensayo - relacionado con la investigación Violencia escolar: discriminación, intimidación y responsabilidad (CROCHÍK, 2013) - se centra en la violencia escolar presente en el acoso escolar. Examinamos especialmente las concepciones de educadores (maestros y coordinadores pedagógicos) de las $8^{\mathrm{a}}$ series $/ 9^{\circ}$ años de tres escuelas estatales en la ciudad de Ananindeua (PA) sobre temas relacionados con el acoso escolar. Tales concepciones se plantearon a través de entrevistas semiestructuradas y se centraron en la percepción de estos educadores acerca de: las causas de la intimidación; el perfil de los estudiantes que atacan y / o son atacados; sobre si los estudiantes en situación de inclusión son victimizados tanto como los otros estudiantes en las escuelas en las que trabajan y, finalmente, sobre posibles acciones para combatir el acoso escolar. El análisis de estas concepciones se lleva a cabo desde el marco de referencia de la teoría crítica de la sociedad, en particular, de la investigación social empírica, propuesta por Adorno, Horkheimer y Marcuse.

Palabras clave: Teoría Crítica de de la Sociedad; Violencia Escolar; Discriminación Y PREJUICIO.

\section{NOTAS INTRODUTÓRIAS}

As concepções a que nos reportamos - acerca da violência escolar presente no bullying - integram os dados parciais da pesquisa intitulada Violência Escolar e Direitos Humanos, ${ }^{1}$ que vem sendo realizada nos municípios de Ananindeua e Belém (PA). Para efeito da composição deste ensaio, referimo-nos às concepções de professores e coordenadores pedagógicos de três escolas da rede pública do Estado situadas em Ananindeua, ${ }^{2}$ levantadas por meio de entrevistas semiestruturadas ${ }^{3}$ no período compreendido entre 2014-2016. Em cada uma das escolas entrevistamos três professores (sendo um de Língua Portuguesa, um de Artes e um de Educação Física), além das Coordenadoras Pedagógicas das mesmas escolas, tendo como objetivo caracterizar o bullying na ótica desses sujeitos.

Apenas para efeito da construção deste ensaio, isolamos as entrevistas dos demais instrumentos utilizados para a realização da pesquisa a que nos referimos, ${ }^{4}$ que foi erguido em

1 A pesquisa Violência Escolar e Direitos Humanos está em curso desde 2014. Note-se que a pesquisa é uma replicação da investigação Violencia Escolar: discriminação, bullying e responsabilidade, coordenada por Crochík (2013) e tem sido replicada, igualmente, em outros municípios/Estados.

2 As demais entrevistas realizadas ao final do ano de 2016, em duas escolas da rede pública de Belém (PA), encontram-se ainda em fase de sistematização para posterior análise e divulgação.

3 Conforme Crochík (2013, p. 22), a adequação entre as entrevistas semiestruturadas e a pesquisa em pauta deve-se ao fato de as mesmas terem "[...] a vantagem de serem flexíveis e permitirem ao pesquisador a inclusão de novas questões não pensadas anteriormente e não fazer outras que eram previstas, dependendo das respostas dos entrevistados" (ROBSON, 2002 apud CROCHÍK, 2013, p. 21).

4 Para além das entrevistas, foram utilizados na pesquisa outros cinco instrumentos - construídos por Crochík, 2013 -, de natureza quantitativa: Escala do Fascismo, Escala da Identificação do bullying; da Identificação das Hierarquias Escolares; da Autonomia frente à Autoridade Escolar e a das Atitudes frente aos alunos em situação de inclusão. 
torno de quatro momentos: estas breves notas introdutórias, situando a pesquisa e seu estágio atual; os sujeitos, materiais e método da pesquisa; o bullying na voz dos educadores, em que expomos o conteúdo das respostas dos educadores às questões das entrevistas, respostas que constituem suas concepções acerca do objeto a respeito do qual nos indagamos e, finalmente, a modo de conclusão, redigimos fragmentos intitulados Em torno das particularidades expressas nas vozes dos educadores: um ensaio do pensamento, uma elaboração acerca de temas, conceitos e problemas emergidos do conteúdo expresso pelos educadores.

\section{Sobre OS SUJEITOS, MATERIAIS E A PESQUISA SOCIAL EMPÍRICA}

O universo da pesquisa é composto por um total de 14 educadores (professores e coordenadores pedagógicos) de três escolas públicas do município de Ananindeua. Esses educadores são professores de três disciplinas (Língua Portuguesa, Artes e Educação Física) e Coordenadoras Pedagógicas das respectivas escolas. ${ }^{5}$ Os instrumentos da pesquisa utilizados junto aos educadores foram: a) coleta dos dados pessoais dos professores e coordenadores pedagógicos (sexo, idade, cargo ocupado, nome da escola em que trabalham, formação, tempo de magistério e há quanto tempo cada um dos educadores entrevistados leciona na escola alvo da pesquisa) e b) entrevistas semiestruturadas. As entrevistas são estruturadas em torno de seis questões: 1) você testemunhou muitos casos de bullying (intimidação) nesta escola?; 2) por que isso ocorre?; 3) quem são os alunos que agridem?; 4) quem são os alunos agredidos?; 5) os alunos em situação de inclusão têm sido alvo do bullying tanto quanto os outros alunos? e 6) o que é necessário fazer para combatê-lo e qual deve ser o papel das autoridades?

Conforme Crochík (2013, p. 22), a adequação entre as entrevistas semiestruturadas e a pesquisa em pauta deve-se ao fato de as mesmas terem:

[...] a vantagem de serem flexíveis e permitirem ao pesquisador a inclusão de novas questões não pensadas anteriormente e não fazer outras que eram previstas, dependendo das respostas dos entrevistados (ROBSON, 2002 apud CROCHÍK, 2013, p. 21).

Cumpre, ainda, notar que, para cada uma das entrevistas realizadas, seguimos cuidados éticos ${ }^{6}$ propostos por Crochík (2013, p. 22).

5 Em uma das escolas (Escola B) participaram duas coordenadoras - dado uma das mesmas estar há pouco tempo na escola - e a professora responsável pela Sala de Atendimento Educacional Especializado.

6 A este respeito, registramos as proposições de Crochík (2013, p. 22): "Para participar da pesquisa, os sujeitos deverão assinar o Termo de Consentimento Livre e Esclarecido [...]; quando forem menores de idade - caso dos alunos - solicitaremos a assinatura dos responsáveis legais dos alunos, ou se não for possível, a assinatura dos responsáveis pela escola; o sigilo sobre os dados quer dos sujeitos, quer das escolas e o anonimato dos mesmos serão assegurados; cada sujeito poderá abandonar a pesquisa se assim julgar conveniente, sem nenhum ônus [...]; ao fim da pesquisa, será realizado um seminário para o qual todas as escolas participantes serão convidadas, para expor os resultados da pesquisa, com o cuidado acima exposto de não revelar nem a identidade dos sujeitos nem das escolas às quais pertencem". Acerca das questões éticas, ressaltamos, também, que o projeto da pesquisa em curso - ao qual se vinculam os dados aqui reportados - teve o Protocolo de Pesquisa $\mathrm{n}^{\circ}$. 066/2011 aprovado pelo Comitê Ético em Pesquisas com Seres Humanos da Pontifícia Universidade Católica de São Paulo em Reunião Ordinária de 28 de março de 2011. 
Cada uma das entrevistas foi devidamente registrada (por meio de gravador, para posterior transcrição) e, posteriormente, editadas e analisadas. No que concerne às entrevistas com os educadores (professores e coordenadores pedagógicos), levantamos - ao iniciarmos as entrevistas - os dados pessoais de cada um deles. Assim, além do nome de cada um, perguntamos e registramos: idade; nome da escola em que trabalham; cargo ocupado; formação acadêmica; tempo de magistério e tempo de trabalho na escola. Dos educadores entrevistados, 3 (três) são do sexo masculino e 11 (onze) do sexo feminino. A média de idade dos educadores é de 41,3 anos (a mais nova é coordenadora pedagógica e tem 27 anos e o mais velho, Professor B3, tem 59 anos); o tempo médio de formação dos mesmos é 15,16 anos (variando entre cinco a 25 anos de magistério). A média do tempo em que trabalham nas escolas alvo da pesquisa é de 9,63 anos. Todos os educadores possuem formação superior, sendo que três deles (B1; A3 e B4) realizaram cursos de especialização. O Quadro 1 sistematiza os dados pessoais dos professores entrevistados.

Quadro 1 - Dados dos educadores

\begin{tabular}{|c|c|c|c|c|}
\hline Escola/ Cargo & Idade & Formação & $\begin{array}{l}\text { Tempo } \\
\text { Magistério }\end{array}$ & Tempo Escola \\
\hline Coordenadora Pedagógica A1 & $30 \mathrm{a}$ & Pedagogia & 8 anos & 3 anos \\
\hline Professora de Artes A2 & $35 \mathrm{a}$ & Ed. Artística (Hab. Música) & 10 anos & 7 anos \\
\hline Professora de Língua Portuguesa A3 & $49 \mathrm{a}$ & Letras e Filosofia & 25 anos & 22 anos \\
\hline Professor de Educação Física A4 & $39 \mathrm{a}$ & $\begin{array}{l}\text { Educação Física (Pós-gra- } \\
\text { duação Pedagogia) }\end{array}$ & 15 anos & 4 anos \\
\hline Coordenadora Pedagógica B & ---- & ---- & ---- & --- \\
\hline Coordenadora Pedagógica B1 & $27 \mathrm{a}$ & $\begin{array}{l}\text { Pedagogia (Esp. em Ges- } \\
\text { tão Escolar e Educação } \\
\text { Inclusiva) }\end{array}$ & 5 anos & 3 anos \\
\hline Professor de Artes B2 & $40 \mathrm{a}$ & $\begin{array}{l}\text { Licenciatura em Educação } \\
\text { Artística }\end{array}$ & 11 anos & 10 anos \\
\hline Professor de Educação Física B3 & $59 \mathrm{a}$ & Educação Física & 24 anos & 4 anos \\
\hline Professora Língua Portuguesa B4 & $47 \mathrm{a}$ & $\begin{array}{l}\text { Licenciada Plena em LP } \\
\text { e LI (Pós-Graduação em } \\
\text { Gestão Escolar) }\end{array}$ & 22 anos & 19 anos \\
\hline Professora Educação Inclusiva B5 & --- & $\begin{array}{ll}--- \\
--\end{array}$ & --- & --- \\
\hline Coordenadora Pedagógica C1 & $40 \mathrm{a}$ & Licenciatura em Pedagogia & 14 anos & --- \\
\hline Professora de Artes C2 & $39 \mathrm{a}$ & $\begin{array}{l}\text { Artes Plásticas, Educação } \\
\text { Artística/ Hab. Artes Plás- } \\
\text { ticas }\end{array}$ & 10 anos & 10 anos \\
\hline Professora Língua Portuguesa C3 & $45 \mathrm{a}$ & $\begin{array}{l}\text { Licenciatura em Letras } \\
\text { (LP) }\end{array}$ & 16 anos & 9 anos \\
\hline Professora de Educação Física C4 & $46 \mathrm{a}$ & $\begin{array}{l}\text { Licenciatura em Educação } \\
\text { Física }\end{array}$ & 22 anos & 15 anos \\
\hline Médias & $\begin{array}{l}41,33 \\
\mathrm{a}\end{array}$ & ---- & $15,16 \mathrm{a}$ & 9,63 a \\
\hline
\end{tabular}

Fonte: Giordano, 2017. 
Note-se, relativamente ao Quadro 1, que codificamos as três escolas como Escola A, B e C e seus respectivos educadores como Coordenadora A1, Professora de Artes A2 e assim por diante, para explicitar que tais educadores trabalham nas escolas indicadas pelas letras $(\mathrm{A}, \mathrm{B}$ e $\mathrm{C}){ }^{7}$

Ao nos referirmos às questões que, orientadas pelo quadro de referências da Teoria Crítica da Sociedade, implicam valores, como expressos nas concepções dos educadores, é uma exigência compreender o singular e o particular analisando o nexo e o antagonismo entre totalidade social e os sujeitos. Assim, segundo Maar (2012), em conformidade com a dialética negativa - no interior da qual se observa o primado do objeto na relação entre sujeito e objeto - a aparência (que não é a essência) tem a função de reafirmar o vigente por encobrir as mediações sociais ou os pressupostos sociopolíticos constitutivos do indivíduo, estabelecendo, pois, uma ilusão socialmente necessária. Cabe à dialética negativa possibilitar ao pensamento ir além dessa aparência. Desse modo, as opiniões, os comportamentos e as motivações, que expressam a subjetividade dos sujeitos participantes da pesquisa não são compreendidos isoladamente, mas, inseridos no contexto sócio-histórico. Acerca da mesma questão, Marcuse (1973) colabora afirmando os aspectos de uma teoria - cuja natureza é a de uma crítica da sociedade que, devido à objetividade histórica - que tem problemas implicados na investigação e análise dos fenômenos sociais que surgem relacionados ao julgamento de valores em dois pontos:

1) o julgamento de que a vida humana vale a pena ser vivida, ou, melhor, pode ser ou deve ser tornada digna de se viver. Este julgamento alicerça todo esforço intelectual; é apriorístico para a teoria social, e sua rejeição (que é perfeitamente lógica) rejeita a própria teoria; 2) o julgamento de que, em determinada sociedade, existem possibilidades específicas de melhorar a vida humana e modos e meios específicos de realizar essas possibilidades. A análise crítica tem de demonstrar a validez objetiva desses julgamentos, tendo a demonstração de se processar em bases empíricas. A sociedade estabelecida dispõe de uma quantidade e uma qualidade determináveis de recursos intelectuais e materiais. Como podem ser esses recursos utilizados para o máximo desenvolvimento e satisfação das necessidades e faculdades individuais com o mínimo de labuta e miséria? Teoria social é teoria histórica, e história é a esfera da possibilidade na esfera da necessidade. Por isso, dentre as várias maneiras possíveis e reais de organizar e utilizar os recursos disponíveis, quais oferecem a maior possibilidade de ótimo desenvolvimento? (MARCUSE, 1973, p. 14-15).

7 Observe-se a ausência dos dados relativos à Professora B5, da Escola B e à Coordenadora Pedagógica B da mesma escola. Relativamente à Professora B5, tal ausência justifica-se em virtude de, com a mesma, termos tido apenas uma conversa (porém gravada com a devida autorização da professora) haja vista a dificuldade que tivemos para compreender, na referida escola, a questão do bullying em relação aos alunos em situação de inclusão. Já em relação a uma das Coordenadoras entrevistadas (Coordenadora B), por sugestão da mesma, que estava há apenas um ano na Escola B, entrevistamos outra Coordenadora (Coordenadora B1). Por questões técnicas, os dados pessoais da Coordenadora B não foram devidamente registrados e, posteriormente, não a encontramos mais na Escola para podermos completá-los. 
A necessidade é um dos constitutivos que nos movem. Entretanto, para além das necessidades vitais, tornadas individuais, é preciso identificarmo-nos com a ordem estabelecida e com a da labuta incessante (de produção e consumo do desperdício), entre tantas outras que se fortalecem com a mesma intensidade que a necessidade que exige libertação dessa organização é sufocada. Segundo Adorno (2015, p. 234), em Teses sobre a necessidade "Na sociedade capitalista, produzir para necessidade em sua forma mediada e, assim, fixada pelo mercado é um dos principais meios de forçar os seres humanos a fazer o que lhe é imposto". Nesse sentido, considerando a relação entre necessidade e satisfação é também necessário analisar as contradições de sua constituição na formação humana e seu nexo com a totalidade do processo social (ADORNO, 2015). Se as necessidades monopolizadas e os comportamentos humanos têm servido à manutenção da totalidade estabelecida, torna-se urgente a investigação dos fatores psicossociais que nos constituem, de modo a favorecer o surgimento de necessidades radicais por uma transcendência possível que só emergirá mediante o conhecimento do que nos constitui e de que outra realidade é possível.

No mesmo andamento, compartilhamos do escrito por Horkheimer, nos idos de 1968, em Prefácio para a Reedição de Teoria Crítica: uma documentação (HORKHEIMER, 1990, p. 3):

\footnotetext{
Não pouco dos meus impulsos são os mesmos da juventude atual: anseio pelo melhor, por uma sociedade justa, relutância na aceitação do existente. Compartilho também dos escrúpulos contra a forma de educação nas escolas, no ensino superior e nas universidades. A diferença reside na conduta frente à violência, que na sua impotência faz arranjos com os antagonistas. A bem da verdade, a mim me parece porém imprescindível frisar, abertamente, que a problemática democracia, apesar de todas as suas falhas, sempre é melhor que a ditadura a que levaria hoje a subversão. [...] Proteger, preservar, ampliar, se possível, a limitada e efêmera liberdade do indivíduo consciente das crescentes ameaças a ela é muito mais urgente que negá-la abstratamente ou, pior ainda, pô-la em perigo mediante ações desesperadas (Grifo nosso).
}

A socialização dos dados da pesquisa até o momento levantados, bem como, as disposições já indicadas nos movem para registrar e pensar as particularidades das concepções dos educadores acerca da violência sob a forma do bullying em algumas de nossas escolas.

\section{O BULLYING NA VOZ DOS EDUCADORES}

Na luta travada pela não conversão da superficialidade em essência ou em universalidade, cabe destacar que não nos colocamos como árbitras da verdade ou destituídas de conhecimento da realidade em que nos encontramos e que se encontra a escola - instituição de ensino construída e socialmente determinada. Somos educadoras, com pouco e com muito tempo de experiência na educação. Educadoras tanto quanto aqueles que nos forneceram o material (suas subjetividades e concepções) sobre o qual nos debruçamos. Somos, pois, seres sociais historicamente constituídos. Ao nos debruçarmos sobre este material - o 
bullying na voz dos educadores - expressamos, também, suas concepções sobre os alunos. Os intercâmbios feitos a partir daí expressam, sem dúvida, a nós mesmas posto buscarmos desnudar os significados do outro de nós, desnudando-nos a nós próprias. Cabe, contudo, lembrarmo-nos da salvaguarda de Adorno (1994, p. 172):

\section{A mais simples reflexão sobre a vida da consciência pode ilustrar o quão pouco se pode captar, com a rede conceitual científica, conhecimentos que não são, em absoluto, meros palpites desconchavados, meras impressões desconexas.}

Assim, entre dimensões e limites visíveis ou invisíveis de nosso esforço - que objetiva compreender a particularidade da consciência viva dos educadores - destacamos que, antes de penetrarmos as concepções dos educadores, perguntamos às coordenadoras, em cada uma das escolas, sobre o Projeto Político Pedagógico (PPP) das mesmas e, por nossas observações e/ou segundo as coordenadoras, notamos que os mesmos estão obsoletos ou não existem. Tal observação é, fundamentalmente, de natureza político-pedagógica, uma vez que uma escola que se pretenda democrática não se reduz a um conjunto de intenções desarticuladas da realidade e do que, na realidade, se quer realizar (o que está inscrito na palavra projeto). Na Escola A, o PPP é de 2010 e, segundo a Coordenadora A1, uma tentativa para a reformulação do mesmo está em curso junto aos dois demais coordenadores: "A gente começou, mas deu uma parada pela falta de disponibilidade mesmo de reunir nós três [...]" (COORDENADORA A1). A Coordenação da Escola B afirmou que o PPP não foi elaborado no ano atual (2016), mas alude ser um ideal futuro. ${ }^{8} \mathrm{~A}$ Coordenadora $\mathrm{C} 1$ não nos forneceu muitas informações acerca do PPP e da relação entre escola e comunidade, mas observamos não haver projeto em desenvolvimento na escola, seja oriundo da própria instituição ou orientado pela Secretaria Estadual de Educação (SEDUC/PA). Perguntamo-nos, pois, onde estão a comunidade escolar, as famílias, haja vista os PPP's não terem sido elaborados e, em qualquer das três escolas pesquisadas, sequer menciona-se a convocação da comunidade e dos membros da escola. Em seguida a esse primeiro contato, demos início à pesquisa, por meio da realização das entrevistas.

Nossa primeira questão aos educadores foi: já testemunharam muitos casos de bullying (intimidação) na escola em que trabalham? Todos os educadores responderam afirmativamente, ainda que alguns tenham hesitado para responder "sim". Optaram por citar casos de agressão, homofobia, preconceito ou de apelidação. Sistematizamos os tipos de bullying que ou os educadores admitem ter tomado conhecimento (mas, não reconhecem ter presenciado) ou presenciaram. São eles: intimidação pela força; empurrões; preconceito e racismo (mencionados uma vez pelos educadores); xingamentos e homofobia (duas vezes); agressões (três vezes) e apelidos (seis vezes). Algumas manifestações de bullying foram citadas mais pelas Coordenadoras do que pelos Professores, a exemplo da Coordenadora

8 A Coordenadora B mencionou alguns projetos contidos no PPP, propostos pela Secretaria Estadual de Educação às escolas estaduais, como: Música na Escola, Família na Escola, Mais Educação, Olimpíadas de Matemática e de Lingua Portuguesa. Tais projetos são indicados como possibilidades para o combate à manifestação do bullying. 
A1, que mencionou casos de perseguição ao homossexual e ao negro em sala de aula. Na Escola B, de acordo com a Coordenadora B, a manifestação da discriminação inicia como "brincadeira" por meio de apelidos carregados de estereótipos relacionados à cor, tipo físico ou à orientação sexual e avança em direção à agressão física. ${ }^{9}$ Segundo os professores da Escola $\mathrm{C}$, apelidos relacionados à orientação sexual são frequentes e estão relacionados à questão de valores familiares. Entre as respostas afirmativas, a mais enfática relativamente à existência do bullying - e particularmente, em relação aos alunos em situação de inclusão - foi a da professora da Sala de Atendimento Educacional Especializado: "Eles começam a fazer essa violência, a gente já começa a verificar uma violência psicológica dos colegas em relação a esse aluno que tem uma deficiência"10 (PROFESSORA B5).

Ao responderem ao motivo da ocorrência do bullying, oito educadores indicaram a família como sendo sua causa primeira e dois apresentaram-na como uma entre outras causas. A família é indicada como desestruturada, como instituição em que o pai está ausente ou que submete o adolescente a algum tipo de violência, fazendo com que o mesmo a reproduza ao relacionar-se com seus pares. As demais causas para o bullying, segundo os educadores, relacionam-se à comunidade violenta, intolerância, preconceito, defesa, brincadeira ou coisa de idade (cada fator foi indicado uma vez); diferenças físicas e econômicas (duas indicações); poder (três); cultura (quatro). Tais respostas revelam, na verdade, não propriamente o porquê da ocorrência do bullying, mas, as concepções dos educadores acerca da família ou da comunidade em que os alunos estão inseridos. Cabe a ressalva de que os motivos, sempre de ordem particular, não são relacionados à totalidade social. É como se os alunos e a comunidade não fizessem parte de uma sociedade nem fossem afetados por ela. Os educadores reconhecem que a estruturação da família e da comunidade afeta o comportamento e a atitude dos alunos, porém, não reconhecem que o modo como a sociedade funciona e é estruturada atinge todos os grupos de formação e suas determinações adentram às escolas. A Professora B5, responsável pela Sala do AEE, logo após ter referido a questão social como causa primeira do bullying, ampliou sua resposta até alcançar a ausência de estrutura familiar - parecendo dar a esta ausência maior importância. Em seguida, atribui o mesmo a questões ligadas ao consumo de drogas e à genética. Dado, em alguns momentos, a fala estar interrompida, não se pode afirmar que a mesma, ao abordar o Estatuto da Criança e do Adolescente (ECA), defenda a redução da maioridade penal, bem como, a possibilidade de o indivíduo já "vir pronto" (sic) "apresentando esses sintomas" (sic). Suas palavras:

São alunos que têm já laudos, com dois, três CID’s. 'Gente, o que está acontecendo?’ A gente vive uma cobrança nessa sociedade [...]. E essa desestruturação

9 A Professora C3 introduziu uma diferenciação entre bullying e intimidação. Assim, ao responder à questão, afirmou: "Já! De bullying, sim! Eu acho que de intimidação, exatamente, não. Não foi tão forte assim". Perguntamos à professora se podia relatar algum fato de modo a clarearmos sua resposta e a mesma consentiu: "Posso. No caso, chamar de 'burros' para outros colegas... São esses pequenos maus-tratos que eu considero bullying. No mais, não muitos agressivos, não".

10 Todos os grifos são referentes às ênfases na fala dos educadores. 
familiar, a questão das drogas e fora a questão genética. Às vezes, que a pessoa vem já apresentando esses sintomas, então, eu acho que a escola, em si, tem que se trabalhar (PROFESSORA B5).

Além de indicar os fatores implicados no bullying já mencionados, a Coordenadora B1 sugeriu que o bullying pode ser consequência da vontade de chamar atenção do pai. A Professora A2 indicou o fator família como causa e afirma que "Muita coisa depende da estrutura familiar, porque a escola tem o papel de ensinar. Educar é com os pais". Disse, ainda, que caso houvesse uma investigação sobre a família com os alunos da escola em que trabalha, perceberíamos que "[...] 70, 80\% dos alunos (e por que não, até $90 \%$ ) sofrem com este problema". Na Escola C, tal relação foi apontada pela Professora C2:

A família desestruturada influencia muito. Tenho certeza! A gente percebe uma criança que não tem um cuidado familiar, a gente percebe no modo como se apresenta na sala, no modo da organização dos seus materiais escolares, a gente vê, percebe que não tem uma pessoa adulta dando apoio (PROFESSORA C2).

Diferentemente desse discurso romântico e a-histórico, a Coordenadora B relacionou o bullying à discriminação, às diferenças físicas. Para a Coordenadora Pedagógica A1, a estrutura da escola, ${ }^{11}$ a homogeneização do aluno, a homofobia (que é um grave problema nessa Escola) e o racismo são as causas do bullying. Na mesma escola, o professor A4, de Educação Física, relacionou o bullying às diferenças entre os sexos, às disputas entre as meninas em relação a um menino, bem como, aos meninos que querem "aparecer" no grupo.

Ao analisarmos as características e atributos dos alunos que agridem e dos que são agredidos, como referidos pelos educadores, unimos o conteúdo das respostas dos mesmos haja vista a similitude nas repostas dos mesmos à terceira e quarta questões. Ao responderem quem são os alunos que agridem, seis educadores voltaram a incidir sobre questões de natureza familiar. Os demais fizeram referência a outros fatores (fundamentalmente, às hierarquias sociais, escolares e de natureza individual - a exemplo das diferenças corporais, comportamentais, econômicas, de gênero e raça) para explicitar quem são os alunos considerados agressores e agredidos. Entre os educadores que afirmaram que os alunos agressores são os que têm problemas familiares, situamos os da Escola A (Coordenadora

11 Os excertos citados a seguir explicitam o que a Coordenadora entende por "estrutura" da Educação: "Como é que a educação está sendo estruturada? Da seguinte forma: o professor, não conhece, muitas vezes, o aluno. Não é dada a oportunidade a todos os alunos naquele espaço. Então, o aluno que é mais esperto, o aluno que tem aquele vínculo com a liderança, ele acaba, de alguma forma, influenciando. Aí, o professor não tem aquela intimidade com a turma para conhecer cada um, como a gente - das séries iniciais - de conhecer, de logo apaziguar. Quando você trabalha com as séries de ensino de fundamental maior, você tem uma dificuldade maior de controle, porque o professor, muitas vezes, não fala o nome dos alunos. É uma luta que eu tenho: eles só falam o número do aluno, entendeu? Então, de alguma forma, ele homogeneíza o aluno dentro daquele espaço lá e aí... [...] muitas vezes, o aluno por não ter esse contato com o professor, ele se sente só naquele espaço, e aí que entra a questão do agressor. Daquele aluno que é mais esperto, que é o 'bam-bambam' da sala. Ele pode falar tudo que quer, fazer tudo que quer. Então aí que surge. É mesmo uma questão do sistema" (COORDENADORA PEDAGÓGICA A1). 
A1 e Professor A4). Uma e outro alegaram que os alunos agressores são provenientes de famílias desestruturadas. A Coordenadora A1 afirma que "Geralmente, o aluno que agride vem de uma família que é desestruturada. Ele tem um problema com a questão do lado paterno. Mora com a avó, ou mora sozinho com a mãe". Acrescentou, ainda, que os agressores "[...] são ou já foram agredidos". Já o Professor A4 afirmou que alunos que agridem vêm de famílias desestruturadas cujos pais são "[...] viciados em droga" e que a "[...] mãe não está nem aí", deixando "[...] os filhos ao Deus dará". Ainda, segundo o professor, "A família não dá um direcionamento pra eles".

A Professora C4 acredita que os agressores são alunos que já foram agredidos, transferindo a outros o que já sofreram. Considera, ainda, que, "[...] às vezes, têm uma mãe intolerante". A Professora C2, também relacionando agressão e família, afirma que os agressores são aqueles em que se percebe "falta de apoio junto ao "laço familiar". Em seguida, relaciona os agressores à "carência financeira" e afetiva:

Eles, as características deles assim que eu possa falar, que eu possa evidenciar pra você são alunos que já têm um estereótipo. Como posso dizer para não usar a palavra 'marginalizado'? São alunos que você percebe que têm certa carência financeira e uma carência de afetividade (PROFESSORA C2).

A Coordenadora Pedagógica B1 e a Professora B4 relacionam os agressores a questões de ordem familiar e acrescentam: "são alunos que precisam de ajuda", "é um pedido de ajuda" (COORDENADORA PEDAGÓGICA B1) ou que "os que agridem são os que precisam de mais auxílio do que os que são agredidos" (PROFESSORA B4).

A Professora A3 afirmou que os alunos que agridem são, em geral, os que "[...] já têm uma vivência no mundo do crime" e que "[...] dizem assim mesmo: 'Quem reclamar vai se entender comigo'. Então, eles dão uma de grandalhões, maiorais e hostilizam os outros colegas, sabe?" A mesma professora também cita como agressores "[...] meninos que têm uma vida econômica melhor porque tem também alunos que são pobrezinhos; aqueles com uma vida econômica melhor se acham melhores que os outros [...] e eles também hostilizam".

$\mathrm{Na}$ questão que objetiva saber se os alunos em situação de inclusão têm sido alvo do bullying tanto quanto os outros alunos, três educadores afirmaram, categoricamente, que não, entre estes, a Coordenadora Pedagógica A. Sete educadores, embora tenham afirmado que não, se estenderam nas respostas, o que nos possibilitou perceber que (a) ou presenciaram/relataram casos de ocorrência de discriminação ou (b) afirmaram que, na escola, os alunos são mais solidários ou "tolerantes" com os alunos com deficiência(s). Cinco educadores afirmaram que sim.

A Coordenadora Pedagógica da Escola A respondeu negativamente, afirmando que os alunos em situação de inclusão ou com deficiência são alvos com menor incidência de bullying. Segundo a Coordenadora A, ao contrário, são tratados com carinho e zelo pelos seus pares. Diferentemente desta, as duas coordenadoras da Escola B responderam positivamente à questão. Uma delas afirmou que os alunos em situação de inclusão são - "mais do que ela mesma poderia supor" - alvos do bullying na Escola. Acrescentou, ainda, que 
os mesmos são, inclusive, alvo de discriminação por parte dos próprios professores (COORDENADORA B1). A Coordenadora Pedagógica C1 afirmou que os alunos em situação de inclusão não são alvos de bullying, e que são bem aceitos. Entretanto, ao discorrer sobre uma situação vivida pelo aluno em situação de inclusão em que ele foi filmado, pois, dançava em sala de aula, relatou tanto a existência do bullying, quanto a ameaça de punição, e o consequente abrandamento da mesma.

O Professor A4, de Educação Física - que não tinha certeza sobre a existência ou não de alunos com deficiência(s), na turma do $9^{\circ}$. ano - foi bem categórico relativamente ao fato de os alunos em situação de inclusão sofrerem bullying mais do que os demais alunos, principalmente, na ausência do professor. A Professora A3 foi terminante ao afirmar que na série/turma pesquisada não havia qualquer aluno em situação de inclusão. Referiu-se a outra escola em que trabalha para afirmar que os alunos são mais solidários com esses alunos Revelou, entretanto, que embora os alunos regulares sejam mais solidários com os alunos com deficiência(s), os primeiros, às vezes, reclamam e afirmam: “[...] 'eu não gosto da escola', por causa dessa vivência, entendeu? Diz que não gosta da escola, mas acha que é necessário aprender, mas não gosta de vir para a escola [em virtude do processo de inclusão]. É assim, é complicado isso" (PROFESSORA A3).

Relativamente à sexta questão, O que é necessário fazer para combater o bullying, os educadores referiram-se a mais de uma proposta como modo de combater essa forma de violência. Por exemplo, cinco educadores mencionaram a importância da família; dois a relação entre família e escola; seis citaram a necessidade de controle por parte dos professores em relação aos alunos. Todos os educadores sugeriram, também, campanhas e diálogos para a conscientização acerca do bullying e dois educadores consideraram necessário maior tolerância e mais políticas públicas objetivando reduzir a manifestação da violência. A punição e a vigilância foram indicadas por dois educadores, inclusive, na forma de policiamento.

A Coordenadora Pedagógica A afirmou que - dado o bullying ser um problema social e da família - só se deve recorrer à punição em último caso.

Acredito que a punição ser o último meio, porque na verdade o problema do bullying é um problema ao mesmo tempo social e ele também é um problema do descaso, pois, geralmente, o aluno que agride é aquele aluno que já é agredido. Ele tem ausência em casa e ele faz isso porque ele quer manifestar a revolta dele [...]. Então, eu acredito que para essa mudança existir a gente tem que ter a família presente na escola [...] ela tem que estar na escola para a gente estar trabalhando juntos, porque quando o aluno vê a mãe, o pai dentro da escola... Ele ainda tem aquela questão, principalmente, na nossa região: o respeito, muitos deles respeitam, tem aquele temor e aí outra coisa que deve ser feita é a questão das políticas públicas direcionadas às escolas publicas, por exemplo, música, esporte, tem que ter esse incentivo [...] mas que possam proporcionar para todos (COORDENADORA PEDAGÓGICAA1).

Referiu-se, ainda, ao longo dessa questão da entrevista, à subtração dos direitos dos alunos, o que "[...] não vem ocorrendo haja vista a desvalorização da Educação e a desmoralização do próprio professor". 
O professor está desmoralizado [como está vendo a condição em que estamos agora] e, ainda mais, quer dizer, a Educação é o último olhar que eles têm é para a Educação, para investir. Deveria ser um dos primeiros porque a Educação não é redentora do mundo, mas ela transforma. Então, eu acredito se tivesse Lazer, Cultura, Educação [...] presente na escola... Trabalhar a questão da humanização, os valores, deixar de lado, por exemplo, de se preocupar muito com o conteúdo programático e direcionar o olhar para a formação humana (COORDENADORA PEDAGÓGICAA1).

A Professora de Artes voltou a referir-se à família, resgatando suas primeiras afirmações da entrevista acerca da desestruturação da família. Segundo a professora, "A fonte de todos esses problemas na escola é a desestrutura familiar". Coerentemente com sua afirmação, continuou: "[...] é necessário mexer na raiz do problema. Em minha opinião, é conscientizar esses pais de que educar um filho é responsabilidade deles." Do mesmo modo, a Professora A3 assevera que é papel da família educar as crianças, desde cedo, para a aceitação das diferenças e que o papel da escola é "complementar ao da família".

Eu não vou dizer que o professor vai ter esse papel de combater. Ele não vai ser o agente principal; agente principal é a família. É a família que tem que educar essas crianças: educar para a tolerância, educar para a aceitação. Eu nem digo 'tolerância' porque quando você 'tolera' você diz assim: 'eu não gosto de ti, mas eu sou obrigada a te suportar'. Eu falo 'aceitação', 'aceitar' o outro, que é diferente de você. E eu acho que é um processo educacional que a família tem que fazer. Isso desde criança e a escola vem só fazer uma complementação (PROFESSORA A3).

O Professor A4 remete-se à autoridade representada pelo professor no passado, afirmando que, atualmente, perdemos o poder de chamar a atenção do aluno "mais rigidamente". A desvalorização da autoridade do professor foi evidenciada na Escola A: de acordo com a Professora A3, um professor foi fisicamente agredido porque não passou uma terceira chamada de prova ao aluno; em outra situação, a família dirigiu-se à direção da escola para exigir que a professora comprovasse a acusação de cola em prova - a professora passaria uma segunda chamada à aluna por tê-la visto colando na prova. Ainda em relação à questão do combate ao bullying e da relação com a autoridade, as duas coordenadoras da Escola B sugerem o diálogo com os alunos, o esclarecimento, bem como, a adoção de um conjunto de ações (às vezes, com caráter punitivo), em parceria com outros órgãos/instituições, a exemplo da própria Secretaria de Educação, Ministério Público e Conselhos Tutelares. Extraímos um excerto da concepção de uma das coordenadoras da Escola B sobre o que fazer para combater o bullying e como pensam a questão do papel das autoridades.

$\mathrm{Eu}$ acho que a gente teria que ter uma maior parceria, né? Porque, enquanto escola, a gente tem maior contato com as crianças que são o futuro da nossa geração. Se o aluno está praticando bullying hoje, aqui, talvez ele chegue à vida adulta e, por uma questão boba, banal, ele fica agressivo. [...] Então, por conta 
disso, o Conselho Tutelar, o Ministério Público, a Secretaria, poderiam articular para otimizar esse processo de educação com o aluno, com a família (COORDENADORA PEDAGÓGICA B1).

Na mesma escola, o Professor de Artes considera que o combate ao bullying se dá por meio do trabalho de conscientização desenvolvido pelos professores e que o papel das autoridades seria o de dar suporte aos professores relativamente à proposição de atividades voltadas ao combate do bullying.

Na Escola C, a Coordenadora Pedagógica C1 afirmou que o combate ao bullying é feito por meio de palestras na igreja (por ser um espaço maior) e que há conversas com o "parceiro da coordenação", um aluno que comunica à Coordenação o que está ocorrendo, o que nos faz pensar a possibilidade de a mesma, inconscientemente, estar designando mais um alvo do bullying que expiará a (ir)responsabilidade do sacrifício de quem? A respeito da questão da satisfação gerada pela agressão, citando Fante, escreve Crochík (2016, p. 219):

\footnotetext{
A satisfação com a agressão é destacada por Fante (2005): 'O bode expiatório constitui-se, para um aluno agressor, num alvo ideal. Sua ansiedade, ausência de defesa e seu choro produzem um forte sentimento de superioridade e de supremacia no agressor, que pode então satisfazer alguns impulsos de vingança... Ao que parece, o agressor sente a mesma satisfação quando ataca ou quando são outros que atacam a vítima (p. 48)'.
}

A Professora de Artes também abordou a importância do diálogo, do respeito visando o combate ao bullying de modo a impedir "[...] o constrangimento, mal-estar, gerando um clima desfavorável para esse aluno, porque afeta o psicológico, o social, [...] e uma série de fatores que vão implicar principalmente na aprendizagem dele". Quanto ao papel das autoridades, também indicou a importância da realização de campanhas e palestras nas escolas. Afirmou, entretanto, não saber se essas ações podem ajudar, pois, “[...] como eu disse, a questão é no hábito familiar. Então, eu acho que deveria começar primeiro lá todo este trabalho" (PROFESSORA C2). Segundo a mesma, "[...] a partir daí, o aluno pode até tentar melhorar, tentar seguir algumas normas da escola" (PROFESSORA C2).

\section{EM TORNO DAS PARTICULARIDADES EXPRESSAS NAS VOZES DOS EDUCADORES: UM ENSAIO DO PENSAMENTO}

Os fragmentos aqui apresentados, conforme já explicitado, envolvem a leitura de temas, problemas e conceitos emergidos das concepções expressas pelos educadores acerca do bullying em suas escolas. Em Tabus acerca do Magistério, Adorno (1995) refere-se à relação de afeto entre professor e alunos, objeto imediato de seu trabalho. Nas sociedades altamente administradas, cuja principal característica é a de uma racionalidade que tudo reduz a valor de troca, deve-se negar o afeto implicado nas relações individuais. Nos excertos das entrevistas lemos sentimentos de frieza, culpa e aversão quer por aqueles com quem mantemos relações, quer pela contrariedade em relação ao nosso trabalho, haja vista, por 
exemplo, segundo os educadores, termos que fazer um trabalho que não é o nosso, mas, o da família. Foram essas as primeiras impressões que saltaram aos nossos olhos na leitura da experiência da pesquisa e do material coligido por meio das entrevistas. Nossas considerações iniciais prestam-se, assim,

[...] no máximo a tornar visíveis algumas dimensões da aversão em relação à profissão de professor, que representam um papel não muito explícito na conhecida crise de renovação do magistério, mas que, talvez até por isto mesmo, são bastante importantes (ADORNO, 1995, p. 97-98).

$\mathrm{Na}$ família, na comunidade, na escola, no grupo ou na sociedade, as relações que os homens estabelecem entre si encontram-se danificadas em virtude da conversão do homem à condição de objeto que o reduz à sua força de trabalho, mercadoria viva. Ao versar sobre os paradoxos de uma psicologia de base marxista, Carone (2016) discorre a respeito desse fato indicando a inexistência do indivíduo. Segundo a autora, o homem objeto e sua heretonomia existem porque é o capital o sujeito do desenvolvimento da realidade social. Desta feita, a condição para a transcendência dessa realidade é a "[...] crítica da reificação da subjetividade humana apontando para a transcendência possível" (CARONE, 2016, p. 111), crítica que implica, igualmente, a teoria, o exame dos fundamentos dessa coisificação do existir humano. Buscamos, pois, a crítica do que constitui nosso fazer junto à educação, bem como, os fundamentos teóricos de nossa individualidade petrificada.

O homem, em busca do progresso, empenhou-se na luta para dominar a natureza e desencantar o mundo, contribuindo para o surgimento do não indivíduo e, por conseguinte, para o esmorecimento da vida que cedeu lugar ao capital. Sem negar os benefícios do desenvolvimento social e tecnológico, é necessário reconhecer a dialética subsumida no progresso, posto que, segundo Horkheimer e Adorno (1985, p. 20), devido à ânsia de substituir o mito pelo saber, o homem transformou-se em objeto, em capital e o esclarecimento - cujo projeto era o de uma vida digna de ser vivida - eliminou a sua própria autoconsciência, pois, esse saber transmutou-se em um poder cuja visada é o capital.

Marcuse (1973), ao analisar o caráter totalitário da sociedade estabelecida ou a dominação do homem sobre si mesmo, afirma que o alcance do domínio que a realidade social exerce sobre o indivíduo tornou-se incomensurável:

\footnotetext{
Essa sociedade é irracional como um todo. Sua produtividade é destruidora do livre desenvolvimento das necessidades e faculdades humanas; sua paz, mantida pela constante ameaça de guerra; seu crescimento, dependente da repressão das possibilidades reais de amenizar a luta pela existência - individual, nacional e internacional [...] As aptidões (intelectuais e materiais) da sociedade contemporânea são incomensuravelmente maiores do que nunca dantes - o que significa que o alcance da dominação da sociedade sobre o indivíduo é incomensuravelmente maior do que nunca dantes (MARCUSE, 1973, p. 14).
}

Tal configuração da realidade sócio-histórica impôs consequências às instituições família e escola, alterando suas antigas funções. De um lado, a família tem sido destituída 
do seu papel e de sua contribuição na formação humana e, devido a motivos sobre os quais não tem controle, vem delegado à escola parte dessa função. A escola já tinha sua função ou contribuição na formação humana: socialização da cultura. À família cabia outra parte dessa socialização na e para a cultura. As duas são complementares na formação humana. Entretanto, a atual configuração histórica da realidade, impulsionada pela sua produtividade destruidora, tem destituído a família e a escola de suas respectivas funções tangentes à emancipação e proporcionado conflitos que nos encaminham à barbárie. Em outras palavras, por compormos uma sociedade contraditória e conflitante que, a partir da tendência dialética do progresso, ordena e favorece determinado tipo de homem, novas formas de violência social podem ser observadas na escola e na família, muito embora possam contribuir - haja vista serem mediadas pelo social - ou para a formação democrática ou para a criação de tipos violentos.

Nas concepções dos educadores que participaram da pesquisa, os fatores ou implicações socioeconômicos foram emudecidos ao indicarem, de modo reducionista, que as causas da violência manifesta no bullying residem, exclusivamente, no modo como a família se estrutura, ou, segundo eles, se desestrutura. Segundo suas concepções, principalmente nas respostas às duas primeiras questões, a violência contida no bullying parece nascer e ser determinada unicamente pela família ou pelas relações que a criança estabelece com os familiares. Nossa hipótese é a de que os próprios educadores não se apreendem como seres nascidos e educados em meio a um contexto familiar danificado, tal como caracterizam o dos alunos. Assim sendo, não se identificam com os alunos no sentido de reconhecerem-se a si próprios, às suas famílias e às famílias dos alunos no interior de um mundo determinado social e historicamente. Dito de outro modo, na concepção dos educadores, a família é impermeável às mudanças histórico-culturais. O problema não é, pois, a ausência de estrutura familiar dos alunos das Escolas A, B ou C de Ananindeua ou de quaisquer municípios. O problema é considerarmos determinada constituição familiar como sendo universal e desconhecermos, assim, a historicidade envolvida na instituição família, bem como nas formas e relações que a mesma vem assumindo. Aspectos importantes dessas modificações são a "liberdade" da mulher ter adentrado no mercado de trabalho, podendo deixar de caber no dístico "recatada e do lar", bem como, o "direito" da criança à Educação e à proteção dos abusos de várias ordens, abusos, muitas vezes, exercidos pelos próprios pais. Cerroni (1971), citando O Capital, de Marx, ao analisar as relações entre a família e a sociedade, afirma:

Não foi o abuso da autoridade paterna o responsável pela exploração direta ou indireta da força de trabalho imatura por parte do capital, mas, pelo contrário, foi o modo capitalista de exploração que incentivou o abuso da autoridade dos pais, eliminando o fundamento econômico correspondente àquela autoridade (MARX apud CERRONI, 1971, p. 28).

Sabemos que, do ponto de vista histórico, o pai era investido de autoridade por ser o provedor econômico e moral. A mãe, por ficar em casa, passar mais tempo com os filhos 
e ser responsável pelas atividades domésticas, era representante do amor, vivendo sonhos utópicos e possibilitando sonhos utópicos ao filho. Entretanto, vivemos tempos em que o pai e a mãe - às vezes, os próprios filhos - saem de casa para trabalhar o dia todo, deixando a cargo de outras pessoas ou de outra instituição a educação dos filhos. Em alguns casos, a família é composta somente pela figura de um adulto. Em outros, cada vez mais famílias têm a mãe como única provedora, que sai de casa para trocar sua força de trabalho pelo mínimo de condições de sobrevivência. Tal fator impede que a mãe disponha de mais tempo para o filho, de modo a contribuir com sua formação. Estes são alguns dos problemas enfrentados pela família real na atualidade e pela criança que nela cresce.

Assim, muito embora a família tenha, de fato, suma importância na formação do indivíduo, não se pode desconsiderar a determinação social que lhe é atribuída para a manutenção da ordem estabelecida. Horkheimer e Adorno (1978) aclaram essa determinação socialmente necessária em virtude de a configuração atual familiar estar prejudicada e afirmam: "A crise da família é a crise da desintegração da humanidade (p. 141)". A crise da família é a crise dos processos sociais, dado a mesma encontrar-se, indissoluvelmente, ligada à totalidade social. Nas palavras dos autores:

\footnotetext{
É ilusório pensar que se possa realizar uma família de pares e iguais numa sociedade em que a sociedade a humanidade não é autônoma e na qual os direitos humanos ainda não tenham sido realizados numa medida concreta e decisiva do que a atual (HORKHEIMER; ADORNO, 1978, p. 147).
}

A cultura é transmitida ao homem pelos processos de onto e filogênese (MARCUSE, 1975). Na família, a criança vive parte significativa desses dois processos mediados pela sociedade e pelos familiares, destacadamente, pela figura de autoridade que, na família, é representada pelo pai; na escola, essa figura será (era!) atribuída ao professor. Contudo, devido às mudanças decisivas na estrutura social, a família tornou-se cada vez menos decisiva na formação do indivíduo e, por isso, o conflito entre pai e filho, originado no seio familiar e decisivo à constituição do homem, já não serve como modelo de orientação. Retornamos o já proposto: o homem convertido em capital e a vida em apêndice. Canevacci (1987, p. 212) explicita que "[...] o enfraquecimento da estrutura da família corresponde à real impotência social do pai (e à respectiva decadência do complexo de Édipo), causada pela expropriação da propriedade privada pelo capital monopolista". Acrescenta o autor que é a ausência de autoridade que motiva a nova autoridade; remete-se, ainda, ao III Reich como resultado da crise política e moral ocorrida na Alemanha após a derrota de 1918 que, ao enfraquecer a figura de autoridade paterna, possibilitou a substituição dessa figura pelo líder fascista.

Se, antes, a família criava e educava, transmitindo normas e valores pessoalmente e, por meio da situação edipiana erigida e o surgimento do superego, faziam a criança travar com o pai e a mãe conflitos originados da relação entre amor e agressão - o que possibilitava uma particularidade e experiências individuais - na atual configuração isso já não ocorre. A formação humana foi cerceada pela realidade social da família, tal como já exposto. A transformação dos processos econômicos ocasionou a modificação do capitalismo 
concorrencial em monopólios, implicando a configuração de uma família com a autoridade fragilizada. No capitalismo concorrencial, eram possíveis experiências individuais e, portanto, o surgimento de um ego capaz de mediar os conflitos entre id, superego e realidade externa e, por extensão, entre Eros e Thanatos. Em sua atual configuração, o capitalismo domina os fatores que têm implicações na formação humana, destituindo a família de sua função, impedindo os conflitos edipianos. Como o homem se desenvolve sem experienciar esses conflitos na família - haja vista ter passado a socializar-se por agentes e agências do todo que são extrafamiliares - instala-se a ausência de modelos de orientação e da figura de autoridade anteriormente incorporada ao pai (MARCUSE, 1975, p. 96; 98). ${ }^{12}$

O papel da autoridade será atribuído a qualquer um que ofereça a força e o poder que foram extorquidos do pai no interior da atual sociedade de monopólios e da conversão do homem em objeto. O pai não é mais o representante da realidade para o filho; não é também aquele que, por ter muito a oferecer, pode exigir muito do filho. Ao que parece, os conflitos entre amor e agressão são impedidos, pois, já não há um alvo específico para direcionar o amor e o ódio ou o medo e o respeito fazendo que o indivíduo direcione o impulso agressivo ou a tendência à agressão a outros alvos. Horkheimer e Adorno (1987, p. 222) contribuem afirmando que:

\begin{abstract}
Na sociedade industrial tardia, todo indivíduo está só: e a expressão que se tornou célebre, a multidão solitária, é um testemunho desse fato. De sua relação com o pai, a criança extrai apenas a idéia abstrata de um poder e de uma força arbitrárias e sem limite, e busca um pai mais forte, mais poderoso que o pai real, o qual já não corresponde à velha imagem; em suma, uma espécie de super-pai, tal como produzido pelas ideologias totalitárias. Também o pai é substituído por poderes coletivos, como o da classe escolar, o da equipe esportiva, do clube, finalmente do Estado. Os jovens manifestam a tendência a se submeterem a qualquer autoridade, não importa o seu conteúdo, contanto que ela ofereça proteção, satisfação narcisista, vantagens materiais e a possibilidade de desafogar em outros o sadismo.
\end{abstract}

Na concepção dos educadores entrevistados, muitas das crianças que agridem assim o fazem por viverem em uma comunidade violenta; por sofrerem agressão de seus pais; pela ausência de afeto. Entre tais fatores, um fator - dois, se considerarmos a convivência em comunidade violenta como exposição à violência - foi especificado por Crochík (2015), a partir de Pinheiro e William (2009), ao afirmar que a exposição à violência entre os pais não está implicada em sua prática, já a violência voltada diretamente às crianças pode torná-las, por um lado, um alvo, no caso das meninas e, por outro, alvo e agressor, no caso dos me-

12 Nas palavras de Marcuse (1975, p. 96): “A organização repressiva dos instintos parece ser coletiva, e o ego parece ser prematuramente socializado por todo um sistema de agentes e agências extrafamiliares. Ainda no nível pré-escolar, as turbas, o rádio e a televisão fixam os padrões para a conformidade e a rebelião; os desvios do padrão são punidos não tanto no seio da família, mas fora e contra a família. Os especialistas dos meios de comunicação com a massa transmitem os valores requeridos; oferece o treino perfeito em eficiência, dureza, personalidade, sonho e romance. Com essa educação, a família deixou de estar em condições de competir". 
ninos. ${ }^{13}$ Cabe destacar que a experiência advinda de um particular não expressa o universal ou não se torna regra geral. Não pesquisamos qualquer estudo que tratasse de questões relacionadas a isso, quer dizer, se as crianças que crescem em comunidades violentas tendem a tornarem-se mais agressivas do que as crianças que não. É preciso considerar, principalmente, que a comunidade não pode ser vista como determinante último. Observamos, ainda, nas vozes dos educadores que estes também são orientados por preconceitos de classe, ao se referirem às vestimentas dos alunos e à falta de cuidado de alguns pais para com seus filhos, especificamente, com aqueles caracterizados como agressores.

Outros alunos, identificados como agressores, foram enquadrados como os "maiorais", os mais fortes. Quando falam dos alunos agressores e dos alunos agredidos, os educadores mencionam, sem perceber, a existência das hierarquias e suas implicações nas relações entre os alunos quanto ao bullying. $\mathrm{O}$ aluno que agride se destaca pela sua força física ou pelo bom desempenho em sala de aula e o aluno agredido foi, quase sempre, considerado o mais frágil, tímido e, em algumas vezes, o aluno com deficiência(s). Tal constatação faz-nos remeter ao que afirma Crochík (2013, p. 7), a partir de Horkheimer e Adorno (1985), sobre o modo e o funcionamento da estrutura social que favorece a perseguição a determinados grupos:

A perseguição aos que parecem frágeis é marca frequente em diversas formas de preconceito, fenômeno esse que compõe boa parte da violência existente em diversas épocas e em distintos lugares (ver Horkheimer e Adorno, 1985). Seria de se esperar que os novos alunos incluídos - sobretudo os que têm deficiência - seriam as vítimas preferenciais do bullying, tal como afirmam Freire et al.

A partir de Horkheimer e Adorno (1985), Crochík (2013, p. 5) comenta que:

A violência se apresenta nas instituições sociais e nos indivíduos: nas instituições, mediada pela hierarquia social que classifica e ordena os homens em conformidade com a classe social a que pertence e às suas competências; a hierarquia social, ao dispor os homens em inferiores e superiores, deve tornar os primeiros submissos e os últimos comandantes; deve-se sublinhar que, na hierarquia, quase todos mandam em alguém e são mandados por outros; no nível individual, isso se expressa pelo sadomasoquismo, que nesse caso suscita o prazer de mandar e o prazer de se submeter.

13 A esse respeito, importa mencionar a revisão de literatura realizada por Crochík (2016, p. 218): “Há diversas pesquisas que revelaram variáveis ligadas quer à prática da intimidação, quer aos alvos. Pinheiro e Willians (2009) citam Berdondini e Smith (1996), que avaliaram aspectos da coesão familiar em alunos vítimas de bullying, alunos autores da intimidação e alunos sem envolvimento em situações de bullying. Os autores concluíram que a ausência do pai tornava mais provável o aluno ser intimidador e que o carinho familiar, expressado pela superproteção, estaria relacionado com a vítima da hostilidade. Freire e col. (2006) apresentam considerações distintas: parece haver relação entre o estatuto de aluno-vítima e famílias com um só ou nenhum dos pais presentes; quanto aos alunos com estatuto de agressores, tendencialmente vivem com ambos os pais". 
A hierarquia manifesta na escola é, também, expressão da social. A sociedade desigual organiza os homens conforme suas aptidões. Na escola, a hierarquia pode aparecer nas tipologias do mais forte e do mais fraco ou conforme o desempenho do aluno nas disciplinas em sala de aula. Adorno (1995) menciona duas tipologias de hierarquias na escola que podem basear-se em estereótipos ou na situação objetiva do professor: uma, a hierarquia oficial - que discrimina, promove, exclui ou segrega em virtude do bom ou mau desempenho nas disciplinas de sala de aula - outra, não oficial - que distingue os alunos conforme seus atributos físicos e de força.

Assim, devido à configuração imposta pela realidade na família, a tendência à agressão ou ao impulso agressivo é funcional à manutenção da sociedade desigual. A usurpação da experiência e da autonomia na constituição do indivíduo - que implica os momentos repressivos da ordem e da organização econômica e sua ideologia - contribuem, cada vez mais, para a formação de personalidades autoritárias (conforme denominação de Adorno e de Horkheimer e Adorno e col. $(1965 ; 1978)$, isto é, indivíduos tendencialmente voltados à violência, bem como para a produção e reprodução da violência com objetivos obscuros ou contrária a uma vida humana digna de ser vivida (ADORNO, 1995). Para Horkheimer e Adorno (1978), a personalidade autoritária pode ser associada à hierarquia e ao prazer em submeter ou em se submeter e afirmam que a personalidade com tendências autoritárias se orienta hierarquicamente e se submete à autoridade moral idealizada pelo grupo, bem como, condena os que nele não se enquadram. São incapazes de reflexão, porque temem que esta lhes tire a segurança que sentem compondo o grupo do qual fazem parte. Há, nesse tipo de personalidade, um desejo inconsciente de destruição, inclusive de si mesmo, que é projetado para o inimigo escolhido ou inventado.

A cultura, no sentido freudiano, permite ao homem, de um lado, libertar-se da relação natural com o mundo das coisas e suas imagens e, de outro, a manutenção da sociedade por meio da transição das representações culturais coletivas. Assim se realizam as possibilidades da repressão e da autonomia na cultura. Contudo, convertida em capital pela indústria cultural, a cultura mais serve à manutenção da realidade social do que à sua superação. Remetemo-nos a Maar (1995, p. 23) para dizer que a cultura, ou melhor,

[...] 'a indústria' cultural é a cultura totalmente convertida em mercadoria, no plano da totalização da estrutura da mercadoria na formação social, inclusive no plano das próprias necessidades sensíveis a que correspondem os valores de uso dos bens na sociedade de consumo. O esclarecimento como consciência de si, como autoconscientização [...] é condicionado culturalmente e, nos termos da indústria cultural, limita-se a uma 'semiformação', a uma falsa experiência restrita ao caráter afirmativo, ao que resulta da satisfação provada pelo consumo dos bens culturais.

Marcuse (1975, p. 36-37) afirma, ainda, que a cultura é a responsável por coagir o homem e a transformá-lo em indivíduo e, posteriormente, em sujeito. Entretanto, como tem fins econômicos, a tendência social estabelecida mantém o indivíduo em processos de socialização ilusórios que são anteriores àqueles que o constituiriam como sujeito. Cor- 
roborando com a mesma proposição, Horkheimer e Adorno (1985, p. 25) afirmam que, a sociedade contemporânea atua ao longo de todo o processo de semiformação humana, fazendo que o indivíduo incorpore necessidades e comportamentos produzidos e fomentados pela cultura que impõe necessidades e comportamentos visando perpetuar a tendência social vigente. Assim sendo, como personalidades formadas no interior das sociedades totalitárias, com um pensar fundado na personificação e na estereotipia, tendemos a perceber as pessoas enquadrando-as em tipologias. Devido a isso, tendemos a reagir com hostilidade a determinadas tipologias que se caracterizam com traços que devem ser negados por não serem aceitos culturalmente ou por não serem compatíveis com os ideais culturais. ${ }^{14}$

Muitos dos atributos direcionados aos alunos agredidos são utilizados para enquadrá-los e, em seguida, rejeitá-los. Tais características, representações e comportamentos não são inatos. Se o indivíduo tende a idealizar o grupo com o qual se identifica e a projetar atributos negativos ao alvo da agressão, é necessário reconhecer a existência de fatores psicossociais neles implicados e suas determinações sociais. Acerca de algumas atitudes que correspondem à agressão, Crochík (2013, p. 39) comenta:

O preconceito é, usualmente, definido como uma atitude, cuja ação correspon-
dente é a discriminação. A discriminação, por sua vez, entre outras formas de
manifestação, se apresenta na segregação e na marginalização. A segregação
significa separação real ou imaginária de alguém ou de um grupo da maioria
ou de outros grupos; a marginalização implica pôr esse alguém ou grupo na
beira. O segregado não faz parte; o marginalizado o faz de maneira precária.
Certamente há segregação na marginalização, mas isso ocorre não criando um
abismo entre os grupos.

Ao serem questionados sobre como combater a manifestação do bullying, muitos educadores não souberam indicar soluções possíveis o que, provavelmente, decorre do fato de os mesmos desconhecerem seus alunos, o fenômeno, suas causas e implicações. Alguns educadores sugeriram a necessidade da tolerância na convivência dos alunos com seus pares e o aprendizado da convivência com os diferentes para a superação do bullying. Outros, entretanto, ao indicarem a tolerância sugeriram, em seguida, que temos que aprender mais do que, simplesmente, tolerá-las. Aprender a conviver com as diferenças em uma sociedade injusta, que prima pela heteronomia, que valoriza a força e o poder e que se funda na desigualdade econômico-social é um aprendizado conflituoso. Daí Silva (2006, p. 431) afirmar que valorizar ou incentivar a tolerância - como se a intolerância fosse a causa de atitudes de agressão ao diferente - é um "cessar-fogo na guerra". Palavras da autora:

A igualdade pede mais que o simples reconhecimento do outro, que, assim sen-
do, cabe enfatizar, se limita à tolerância, já que essa posição não permite que
cada indivíduo se constitua a partir de sua experiência, sem se reduzir a um
insumo da racionalidade instrumental. O sentimento que mais se manifesta nos
tempos atuais é a tolerância como limite do aceitável, quando já poderíamos

14 Ver Adorno (1995; 2015), Freud (2010), Horkheimer; Adorno (1978). 
nos manifestar com solidariedade em relação ao diferente, por ser a diferença a essência de todos nós. $\mathrm{O}$ ‘distinto’ é mantido na sociedade dentro do parâmetro do tolerável ou integrado, e a indiferença é o que resta como condição de sobrevivência, retratando a frieza (SILVA, 2006, p. 431).

Outro aspecto percebido nas vozes dos educadores é o distanciamento entre eles e o objeto de seu trabalho, de natureza político-educativa, o que pode ser verificado, também, pela inexistência do Projeto Político Pedagógico na escola em que trabalham. Tal projeto não visa cercear o educar dos professores; antes, objetiva escolhas, propostas. Mais do que isso: o PPP é a possibilidade da aproximação entre educadores, família e alunos e, também, de reconhecer as problemáticas que carecem discussão e intervenção. Os próprios educadores registraram que se sentem distantes dos alunos e de suas famílias devido à ausência de tempo - quer dos familiares, quer dos membros da escola - fator que torna o PPP ainda mais necessário no sentido de propiciar o envolvimento entre a comunidade e a escola. Se o Projeto Político Pedagógico tem um objetivo educativo e social, a ausência de sua elaboração reflete a desvalorização da socialização da cultura e do combate ao que desta se reflete na escola, a exemplo da violência social.

Ao analisarmos as vozes dos educadores, observamos uma antinomia de práticas de injustiças entre professor e aluno, como indica Adorno (2015, p. 110) ao afirmar que “[...] alunos e professores praticam injustiças uns em relação aos outros". Se nas escolas em que estivemos as práticas de injustiça, na relação entre professor e aluno, não chegaram à agressão física, na relação entre aluno e professor a agressão chegou ao máximo da agressão física porque o professor não se dispôs a fazer uma terceira chamada de prova ao aluno que não justificou sua ausência nas provas anteriores. Em outra situação, os próprios pais contribuíram com a intimidação e a agressão verbal à professora que passaria uma segunda chamada à aluna que estava colando na prova. Ao que parece, a mínima situação de conflito ou de tensão serve à explosão ou a manifestação daquilo que Freud denomina tendência à agressão. De acordo com Freud (2010) e Adorno e colaboradores (1965), a tendência à agressão é resultado da relação entre instinto de morte e a violência sofrida ou incorporada na relação com a autoridade na infância. Adorno (1995) critica, também, o processo educacional que tem fracassado, posto sua configuração contribuir mais para a heteronomia do que para a desbarbarização. Entretanto, o autor ressalva que são as relações que a escola estabelece com a sociedade que podem apontar para a desbarbarização.

No que tange à Educação, Maar (1995) a partir da obra Educação e Emancipação, de Adorno, ressalta que a educação deve ultrapassar e romper com a aliança entre Educação, Ciência e Tecnologia, destruidora do sujeito. Destruidora posto a tecnicidade direcionar-se à formação de seres humanos heterônomos funcionais ao capital. Assim afirma que:

É preciso romper com a educação enquanto mera apropriação de instrumental técnico e receituário para a eficiência, insistindo no aprendizado aberto à elaboração da historia e ao contato com o outro não-idêntico, o diferenciado (MAAR, 1995, p. 27). 
As palavras de Maar nos remetem às concepções dos educadores sobre o objetivo da escola. Nas concepções dos educadores, a família tem a função de educar e a escola a de ensinar. Sem dúvida, existem distinções ou particularidades em tais processos de formação. Entretanto, ambos têm a função de contribuir para a formação humana. À escola cabe a socialização do conhecimento historicamente elaborado e acumulado pela sociedade, incluídos aí, normas, valores, direitos e deveres. Alguns educadores justificaram que, no Ensino Fundamental II, existem poucas oportunidades de experiências entre educadores e alunos porque a turma é grande e o pouco tempo é utilizado pelo professor para a transmissão de conteúdos. Se avaliarmos, entretanto, os dados educacionais brasileiros (por mais questionáveis que sejam a forma e o conteúdo das atuais avaliações educacionais), veremos que a socialização do conhecimento tem sido, cada vez mais, reduzida a menos do que aqueles conhecimentos funcionais ao mercado, à própria manutenção da realidade social. Em outras palavras, estamos atrasados relativamente aos tempos em que disputávamos pela importância da formação técnica (competência) versus formação política. Não fazemos uma coisa nem outra. De toda forma, é preciso reivindicar que os processos educativos escolares ultrapassem o processo de adaptação e caminhem em direção à formação da consciência verdadeira, à formação para a autonomia e para a democracia. Nesse sentido, Adorno (1995, p. 144) ressalta que "A educação por meio da família, na medida em que é consciente, por meio da escola, da universidade teria neste momento de conformismo onipresente muito mais a tarefa de fortalecer a resistência do que fortalecer a adaptação". A crítica a um processo meramente adaptativo não se restringe apenas às escolas em que fizemos a pesquisa, pois somos - nós e os educadores sujeitos da pesquisa - formados no interior do mesmo processo. Assim, não só a família tem fracassado em seu processo de formação devido a implicações sociais; a universidade também tem contribuído com esse mesmo processo, em virtude de a aliança entre a Educação, Ciência e Tecnologia converter - conforme já indicado -, cada vez mais, a educação em mercadoria, reduzindo a educação (quando muito) a conhecimentos técnicos e utilitários. Novamente recordamos Adorno (1995, p. 143):

\begin{abstract}
A educação seria impotente e ideológica se ignorasse o objetivo de adaptação e não preparasse os homens para se orientarem no mundo. Porém ela seria igualmente questionável se ficasse nisto, produzindo nada além de well adjusted people, pessoas bem ajustadas, em conseqüência do que a situação existente se impõe precisamente no que tem de pior.
\end{abstract}

Ensaiamos pensar e apreender temas, conceitos e problemas nas concepções dos educadores acerca da violência no bullying escolar, deixando transparecer a falsidade que nos pareceu subsumida em suas opiniões, pois que professadas sem dúvidas, como se fossem verdades, como afirmações apoiadas de corpo e alma (ADORNO, 1969) como modo de assinalar um (des)fecho em aberto haja vista nossa pesquisa e estudo não se esgotarem nos aspectos aqui discutidos. Verificamos, entretanto, nas particularidades das contradições dos educadores - a exemplo de o bullying ter como causa primeira a ausência de estrutura 
da família e, simultânea e contraditoriamente, ser provocado em virtude das hierarquias escolares e/ou de características individuais e sociais dos alunos (usar óculos, ser magro, gordo, pobre, negro etc.) - a possibilidade de - a partir de uma formação emancipatória dos mesmos, do conhecimento objetivo dos problemas que atravessam o cotidiano escolar, da correção pela experiência do pensamento - superarem suas opiniões, haja vista que "[...] pensar não é uma pura atividade subjetiva, senão essencialmente, $[. .$.$] o processo dialético$ entre sujeito e objeto, no qual ambos os pólos se determinam"15 (ADORNO, 1990, p. 143).

\section{REFERÊNCIAS}

ADORNO, T. W. Ensaio sobre psicologia social e psicanálise. São Paulo: UNESP, 2015. ADORNO, T. W. et al. La personalidad Autoritaria. Buenos Aires: Proyección, 1965. ADORNO, T. W. Educação e Emancipação. Rio de Janeiro: Paz e Terra, 1995. ADORNO, T. W. Opinión, Locura, Sociedad. In: . Intervenciones: nueve modelos de crítica. Venezuela: Monte Ávila, 1969, p. 137-160.

ADORNO, W. T. O ensaio como forma. In: COHN, Gabriel (Org.). Theodor Adorno. São Paulo: Ática, 1994, p. 166-187 (Grandes Cientistas Sociais, 54).

CANEVACCI, M. (Org.). Adorno e Horkheimer. In: . Dialética da Família: Gênese, estrutura e dinâmica de uma instituição repressiva. São Paulo: Brasiliense, 1987, p. 211-212.

CARONE, I. De Frankfurt à Budapeste: os paradoxos de uma psicologia de base marxista. In: Psicologia - USP. São Paulo, 2(1/2): p. 111-120, 1991. Disponível em: $<$ http://pepsic. bvsalud.org/scielo.php?script $=$ sci_arttext\&pid $=$ S1678-51771991000100010\&lng $=$ pt\&nr $\underline{\mathrm{m}=\mathrm{iso}}>$. Acesso em: 12 ago. 2015.

CERRONI, U. Considerações sobre a relação família-sociedade. In: VÁRIOS. A crise da família e o futuro das relações entre os sexos. Tradução Giseh Vianna KONDER. Rio de Janeiro: Paz e Terra, 1971, p. 11-50.

CROCHIK, J. L. Fatores psicológicos e sociais associados ao bullying. Rev. Psicol. Po-

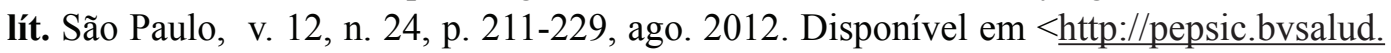
org/scielo.php?script=sci_arttext\&pid=S1519-549X2012000200003\&lng=pt\&nrm=iso $>$. Acesso: 10 mar. 2016.

CROCHIK, J. L. "Violência Escolar: discriminação, bullying e responsabilidade." Projeto de Pesquisa. São Paulo: USP, 2013 (impresso).

FREUD, S. O mal-estar na civilização, novas conferências introdutórias à psicanálise e outros textos (1930-1936). São Paulo: Companhia das Letras, 2010.

Tradução livre das autoras. 
GIORDANO, R. Violência Escolar e Direitos Humanos. Projeto de Pesquisa. Belém: UFPA, 2014 (impresso).

HORKHEIMER, M. Prefácio para a Reedição. In: . Teoria Crítica: uma documentação. São Paulo: Perspectiva: EDUSP, 1990 (v. 1), p. 1-5.

HORKHEIMER, M.; ADORNO, T. W. (1956). Temas Básicos de Sociologia. São Paulo: Cultrix, 1978.

HORKHEIMER, M.; ADORNO, T. W. Sociologia da família. In: . CANEVACCI, M. (Org.). Dialética da Família: Gênese, estrutura e dinâmica de uma instituição repressiva. Editora Brasiliense, 1987, p. 213-222.

HORKHEIMER, M.; ADORNO, Th. O Conceito de Esclarecimento. In: . Dialética do Esclarecimento: Fragmentos Filosóficos. Tradução: Guido Antonio de Almeida. Rio de Janeiro: Zahar Ed., 1985, p. 19-52.

MAAR, W. L. Á guisa de introdução: Adorno e a experiência formativa. In: Educação e Emancipação. São Paulo: Paz e Terra, 1995, p. 11-29.

MAAR, W. L. Materialismo e o primado do objeto em Adorno. Trans/Form/Ação. São Paulo, v. 29 (2), 2006, p.133-154. Disponível em < $\underline{\text { http://www2.marilia.unesp.br/revistas/ }}$ index.php/transformacao/article/view/919>. Acesso em 12 mar. 2012.

MARCUSE, H. A ideologia da Sociedade Industrial. Rio de Janeiro: Zahar, 1973.

MARCUSE, H. Eros e Civilização. Rio de Janeiro: Zahar: 1996.

SILVA, Luciene M. O estranhamento causado pela deficiência: preconceito e experiência. In: Revista Brasileira de Educação, v. 11 n. 33 set./dez. 2006, p. 424- 561.

\section{Dados das Autoras}

\section{Rosely Cabral Giordano}

Doutora em Psicologia pela Universidade de São Paulo. Docente Associada da Universidade Federal do Pará. Belém/PA - Brasil. rgiordanoss@msn.com

\section{Lana Jennyffer Santos Nazareth}

Graduada em Pedagogia pela Universidade Federal do Pará. Belém/PA - Brasil. lanasanreth@outlook.com

Submetido em: 1-4-2017

Aceito em: 27-6-2017 